Virtual Mentor. January 2005, Volume 7, Number 1.

doi: 10.1001/virtualmentor.2005.7.1.ccas13-0501

Module 5

\title{
Case 5.1: Futile Care-An Inoperable Cancer
}

\section{Case Presentation}

Mrs. Scott, a trim, recently retired teacher who has enjoyed relatively good health, visited Dr. Lee, her general internist, for her annual check-up. She had several complaints including back pain, intermittent nausea, loss of appetite, and fatigue for the last several months. She said her back pain usually followed a meal, and her chart disclosed that she had lost 10 pounds since her last check-up. On physical examination, Dr. Lee was unable to draw any firm conclusions as to the cause of these symptoms. He ordered standard diagnostic blood work which showed mild normochromic anemia and low albumin. Because this is a common finding in several chronic diseases, Dr. Lee told Mrs. Scott they would have to set up an appointment at the hospital for more diagnostic tests. Dr. Lee knew that Mrs. Scott's father had died of pancreatic cancer, and, because she was also a regular smoker, she was at increased risk. Since her symptoms were suggestive of pancreatic cancer, he scheduled her for an abdominal CT scan at the local hospital.

The CT scan confirmed that Mrs. Scott did, in fact, have pancreatic cancer. Dr. Lee waited until Mrs. Scott had dressed. When she asked what the test showed, he told her about the diagnosis of pancreatic cancer. Immediately she said, "I want you to get it removed."

"I've already called for a surgery consult to evaluate the possibility of a surgical resection."

Upon consultation, the surgical oncologist, Dr. Parihar, suggested a biopsy to confirm the diagnosis of pancreatic cancer. After evaluating the CT and the biopsy, he informed Dr. Lee who informed Mrs. Scott that the pancreatic cancer was inoperable. Indeed, the spiral CT indicated that the cancer was locally situated in the body and tail of the pancreas, that it had spread substantially_not only were the local lymph nodes involved, but there were distant metastes. Finally, the CT showed local invasion into the vascular structures - specifically, the superior mesenteric and celiac arteries. In Dr. Lee's judgment, Mrs. Scott had no more than 4-6 months to live.

Even after she was informed by Dr. Lee of the uselessness of surgery for her condition, Mrs. Scott continued to demand surgery to remove the tumor.

\section{What should Dr. Lee do? (select an option)}
A. Allow Dr. Parihar to assume complete care for Mrs. Scott.
B. Urge Dr. Parihar to acquiesce to Mrs. Scott's request for surgery.
C. Reiterate the reasons that surgery is not indicated.
D. Ask Mrs. Scott to discuss why she wants the surgery.
E. Suggest to Mrs. Scott that she should seek a second opinion or transfer to another hospital.

The people and events in this case are fictional. Resemblance to real events or to names of people, living or dead, is entirely coincidental. The viewpoints expressed on this site are those of the authors and do not necessarily reflect the views and policies of the AMA. 
Virtual Mentor. January 2005, Volume 7, Number 1.

doi: 10.1001/virtualmentor.2005.7.1.ccas13a-0501

Module 5

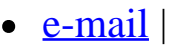

\section{Case 5.1: Futile Care-An Inoperable Cancer}

\section{Option Assessment}

A. Allowing Dr. Pandihar to assume complete care for Mrs. Scott is to be avoided. Dr. Lee's withdrawal from Mrs. Scott's care at this time may violate several of the Code's guidelines and cause her to feel abandoned and helpless. Opinion 8.11 "Neglect of Patient" prohibits neglecting patients once they have come under one's care. Opinions 2.21 "Euthanasia" and 2.211 "Physician-Assisted Suicide" caution physicians not to abandon patients once it has been determined that cure is impossible. Patients with terminal illnesses need multidisciplinary support; their primary physicians should not withdraw from participating in their care at this time.

B. Urging Dr. Parihar to acquiesce to Mrs. Scott's requests should be avoided; it is not supported by the Code. Opinion 2.037, "Medical Futility in End-of-Life Care" states: "Attempts should be made to negotiate disagreements if they arise, and to reach resolution within all parties' acceptable limits, with the assistance of consultants as appropriate." Moreover, Opinion 2.19 "Unnecessary Medical Services" states that "Physicians should not provide, prescribe, or seek compensation for services that they know are unnecessary."

C. Reiterating the reasons that surgery is not indicated is preferable. Code Opinion 2.037, "Medical Futility in Endof-Life Care" states: "Joint decision-making should occur between patient or proxy and physician to the maximum extent possible...Attempts should be made to negotiate disagreements if they arise, and to reach resolution within all parties' acceptable limits, with the assistance of consultants as appropriate." Attempts to reach agreement may well start by further explaining to Mrs. Scott the reasons why surgery will not achieve the medical goal she desires.

D. Asking Mrs. Scott to discuss why she wants surgery is acceptable and is supported by the Code in Opinion 2.037, "Medical Futility in End-of-Life Care," which states: "Joint decision-making should occur between patient or proxy and physician to the maximum extent possible...Attempts should be made to negotiate disagreements if they arise, and to reach resolution within all parties' acceptable limits, with the assistance of consultants as appropriate." Giving Mrs. Scott the opportunity to express the motivations for her wishes is one step in the process in joint decision-making and should provide an opportunity to negotiate the existing disagreement.

E. Suggesting to Mrs. Scott that she should seek transfer to another hospital may be supported by the Code, but, at this point, should be avoided. Opinion 2.037, "Medical Futility in End-of-Life Care" states that "If the process [of negotiating disagreements about futile care] supports the physician's position and the patient/proxy remains unpersuaded, transfer to another institution may be sought and, if done, should be supported by the transferring and receiving institution." It is still too early, however, in the process of discussing her request for an apparently futile surgery to warrant transfer to another institution. 
The people and events in this case are fictional. Resemblance to real events or to names of people, living or dead, is entirely coincidental. The viewpoints expressed on this site are those of the authors and do not necessarily reflect the views and policies of the AMA.

(C) 2005 American Medical Association. All Rights Reserved. 
Virtual Mentor. January 2005, Volume 7, Number 1.

doi: 10.1001/virtualmentor.2005.7.1.ccas13b-0501

Module 5

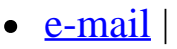

\section{Case 5.1: Futile Care-An Inoperable Cancer}

\section{Option Comparison}

Mrs. Scott may have expectations about the surgery that are unknown to Dr. Lee and Dr. Parihar. Accordingly, option D (having Mrs. Scott discuss her reasons for wanting the surgery) is an acceptable first step. Option C (further explaining why surgery will not achieve Mrs. Scott's medical goals) is the preferred action.

Option B, performing the surgery, should be avoided for a number of reasons including the failure to foster joint decision-making. More importantly, physicians are not ethically obligated to deliver care that they do not think will benefit the patient. Option A-referring Mrs. Scott to Dr. Parihar-may cause her to think she is being abandoned by her physician and provoke feelings of helplessness. Option E should also be avoided at this point in the case. Although it may be necessary later, a more thorough attempt should be made to discuss the issues involved before Mrs. Scott's care is transferred to another physician or hospital.

Preferable: Option C

Acceptable: Option D

Avoid: Options A, B, and E

Additional discussion and information

The people and events in this case are fictional. Resemblance to real events or to names of people, living or dead, is entirely coincidental. The viewpoints expressed on this site are those of the authors and do not necessarily reflect the views and policies of the AMA.

(C) 2005 American Medical Association. All Rights Reserved. 
Virtual Mentor. January 2005, Volume 7, Number 1.

doi: 10.1001/virtualmentor.2005.7.1.ccas13c-0501

Module 5

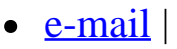

\section{Case 5.1: Futile Care-An Inoperable Cancer}

\section{Additional Information}

In the course of clinical care of a critically ill patient, it may become clear that the patient's condition is terminal and that further intervention will do no more than prolong the dying process. At this point, further intervention is often described as "futile," a term whose meaning depends on a subjective judgment. This judgment arises from considerations about quality of life, which Opinion 2.17, "Quality of Life," clearly leaves to patients: "quality of life, as defined by the patient's interests and values, is a factor to be considered in determining what is best for the individual." Nevertheless, patient decisions about futile or non-futile care do not compel physicians to comply with requests that, in the physician's judgment, meet no treatment or care goals.

For non-terminal situations, Opinion 2.035 defines the limits of physician obligations when patients request an unindicated treatment.

\section{Opinion 2.035, "Futile Care"}

Physicians are not ethically obligated to deliver care that, in their best professional judgment, will not have a reasonable chance of benefiting their patients. Patients should not be given treatments simply because they demand them. Denial of treatment should be justified by reliance on openly stated ethical principles and acceptable standards of care...

For patients with a terminal prognosis, the AMA recommends defining futility on a case-by-case basis, taking full account of the context and individuals involved. The Code, in Opinion 2.037, "Medical Futility in End-of-Life Care," outlines a due process approach to achieving this case-by-case determination:

\section{Opinion 2.037, "Medical Futility in End-of-Life Care"}

To assist in fair and satisfactory decision-making about what constitutes futile intervention:

(1) All health care institutions, whether large or small, should adopt a policy on medical futility; and

(2) Policies on medical futility should follow a due process approach. The following seven steps should be included in such a due process approach to declaring futility in specific cases.

(a) Earnest attempts should be made in advance to deliberate over and negotiate prior understandings between patient, proxy, and physician on what constitutes futile care for the patient, and what falls within acceptable limits for the physician, family, and possibly also the institution 
(b) Joint decision-making should occur between patient or proxy and physician to the maximum extent possible.

(c) Attempts should be made to negotiate disagreements if they arise, and to reach resolution within all parties' acceptable limits, with the assistance of consultants as appropriate.

(d) Involvement of an institutional committee such as the ethics committee should be requested if disagreements are irresolvable.

(e) If the institutional review supports the patient's position and the physician remains unpersuaded, transfer of care to another physician within the institution may be arranged.

(f) If the process supports the physician's position and the patient/proxy remains unpersuaded, transfer to another institution may be sought and, if done, should be supported by the transferring and receiving institution.

(g) If transfer is not possible, the intervention need not be offered.

This procedural approach (or "due process" as it is referred to above) is preferable because in cases of patientphysician disagreement, it can incorporate institutional and community standards for patient benefit. It also allows a hearing for patient or proxy assessments of worthwhile outcomes, and for physicians' or other professionals' intention in treating the patient. Finally, it has the advantage of providing a system for addressing the ethical dilemmas around end-of-life care without immediate recourse to the court system.

\section{$\underline{\text { Next Case }}$}

\section{Module 5 Table of Contents}

The people and events in this case are fictional. Resemblance to real events or to names of people, living or dead, is entirely coincidental. The viewpoints expressed on this site are those of the authors and do not necessarily reflect the views and policies of the AMA.

(C) 2005 American Medical Association. All Rights Reserved. 